\title{
Identifying Dimensions and Their Measuring Items for Library Website Usability Acceptance Model: Instrument Development and Validation
}

\author{
Kokila Harshan Ramanayaka*, Xianqiao Chen, Bing Shi \\ The School of Computer Science \& Technology, Wuhan University of Technology, Hubei, P.R. China. \\ * Corresponding author. Email: kokila@cc.ruh.ac.lk \\ Manuscript submitted August 10, 2017; accepted November 8, 2017. \\ doi: $10.17706 /$ jcp.13.7.750-760
}

\begin{abstract}
A library website plays an enhanced role compared to its traditional physical library while providing a wide variety of library services to its users. Evaluation of library websites is a key to realize the extent of user acceptance to the website and to improve overall quality of website. Usability is a highly recognized factor to determine how easy to use the website. The models of usability evaluations evaluate the ease of use of website operations and see whether the users can perform their tasks competently. Moving on further, this study has been undertaken in context of library websites in Sri Lanka with the main purpose of exploring the relations between different dimensions of website usability and their impact. The study first investigated the common dimensions of website usability together with instrument items to measure dimensions by integrating the findings of an extensive literature review as well as discussions with local experts. The measurement instrument was then empirically validated its reliability and validity for the Sri Lankan library system with the aids of actual library users in Sri Lanka. Descriptive statistics methods and structural equation modelling techniques were applied. The proposed usability evaluation model consisted of the seven dimensions and two to three measurement items for each dimension. It is expected that this model can be used as a library website usability evaluation tool to evaluate the strengths and weaknesses of the website and update the website performance up-to-date.
\end{abstract}

Key words: Library website, performance evaluation, SEM, usability evaluation, web usability.

\section{Introduction}

With the rapid development of internet technology and the gradually accelerating rate of information technology, website of an organization has taken place as a virtual image and a public interface for information seekers around the world as a global gateway to enter the knowledge repositories and achieve required services. Thus the websites have been identified as an easiest and effective way of distributing information and procuring services while effective website enhances greater research impact, serving services on time and attracting visitors to the site as prospective benefits [1]. Therefore, accordingly to the fast changing environment of the technology, organizations need to develop user friendly and well content websites and update the website performance on time [2].

Today, website is considered as lifeline of libraries and websites are mainly used as a virtual image and promotional platform of the library that displays information and services given by a library. Presently, libraries draw attention to promote e-resources, online catalogues, web 2.0 services, and online reference 
services through their websites to achieve the existing challenges of promoting better visibility for their print resources, offering various value added electronic services, and providing an access to quality content in electronic form. In addition, user satisfaction to the website is another big demand for the libraries and user satisfaction can be achieved if the interface and content of the library website have fulfilled with the usability principles [3]. Therefore, developing usable websites meeting with the information and services given is essential for library's success since users satisfy with information and services that provide mainly through websites [4]. Usability is considered as the most important item of the website while it measures the simplicity of the website [5].

In the recent years, usability evaluations, especially, in commercial websites have been conducted to diagnose problems of current websites and to enhance website interfaces by better reflecting user viewpoints. As a result of usability evaluation, a positive attitude to the website and revisit rates can be increased effectively and on the other hand, it supports to reduce website development, maintenance, and support costs also [6]. Furthermore, because of each website has different kind of features and different categories of user requirements, the usability measuring criteria used for evaluating the websites may also different [7]. Moreover, according to the disciplines and environments, different set and number of website usability dimensions with different important levels were taken to measure the usability in specific type of websites in previous studies [4]. Nevertheless, there are no sufficient researches conducted in library websites usability evaluations. Furthermore, in the literature review, it has been found that no any specific research studies conducted related to university or other type of library website usability evaluation in Sri Lanka country context. In this backdrop, the main purpose of this study is to identify common usability measuring dimensions and instrument items that can be used to measure the dimensions of library related websites from previous studies and discussions with local experts and then empirically validate the reliability and validity of identified dimensions and instrument items to examine the accordance of the Sri Lankan library environment from actual users. The remainder of this paper is organized as follows. Section II reviews the prior research on website usability studies and its measurements. Section III presents the objectives of the paper followed by the methodology in Section IV. Subsequently, instrument development and results of analysis are presented in Section V and Section VI respectively to identify and validate usability model's applicability in a real life system. Section VII provides a discussion and implication of findings and applications. The paper is concluded with avenues for future research work in Section VIII.

\section{Related Previous Works}

Web usability can be defined as the degree of user achievement to specific goals in the website with effectiveness, efficiency, and satisfaction [4]. Websites have fulfilled with usability, if the user expected information and services are available; the required task can be fulfilled and completed quickly without facing any errors and easy to remember for next time browsing; feel satisfied; as well as accessible provisions for disabilities [3], [8], [9].

In the last few decades, several usability evaluation studies have been conducted by applying variety of alternative approaches in different countries. For example, studies by Joo, Lin and Lu [9] have developed a usability evaluation model including three dimensions along with 18 measurement items for library websites and tested its reliability and validity from actual users; McGillis and Toms [10] have evaluated academic library website usability with having given task completion from library users; Raward [11] has introduced a user centred design model with usability checklist based on human computer interaction principles for library websites evaluation; George [12] has conducted a usability study for enhanced the Carnegie Mellon University Library website following the think aloud protocol to determine the strengths and weaknesses; King and Jannik [13] have expressed the usability testing process which they followed for evaluate the Georgia Institute of Technology Library; Turnbow et al. [14] have discussed the usage of 
structured analyses, think aloud protocol, user surveys, and card sort protocol while evaluating the usability of the UCLA Library website; Kim [15] has established a usability evaluation framework for institutional repository systems; Buchanan and Salako [16] have introduced a multi method approach usability evaluation framework for digital libraries; Hariri and Norouzi [17] have proposed 22 usability evaluation criteria for digital library user interface usability evaluation; Raju and Harinarayana [18] have made an attempt to identify the usability features of library websites of top science universities around the world. In summary, the importance of website usability evaluations among the perceptions and behaviours of web users can be well identified from the past website usability studies. Though, each study applied different approaches of usability dimensions with different disciplines and measures same dimensions using different measurement items. So, there has a space for further investigations.

\section{Research Objectives}

The main objective of the study is to identify and validate a major measurement instrument dimensions and their measurement items for usability evaluation specific to a library websites in Sri Lanka. The other inter-linked objectives are to:

- Identify a set of measurement dimensions and instrument items to measure the dimensions which can be used for evaluate library websites usability status from an extensive literature review and expert consultation

- Develop an instrument for evaluating the usability of library websites

- Empirically validate the reliability and validity of the developed instrument using the survey data from actual library users in Sri Lanka.

\section{Methodology}

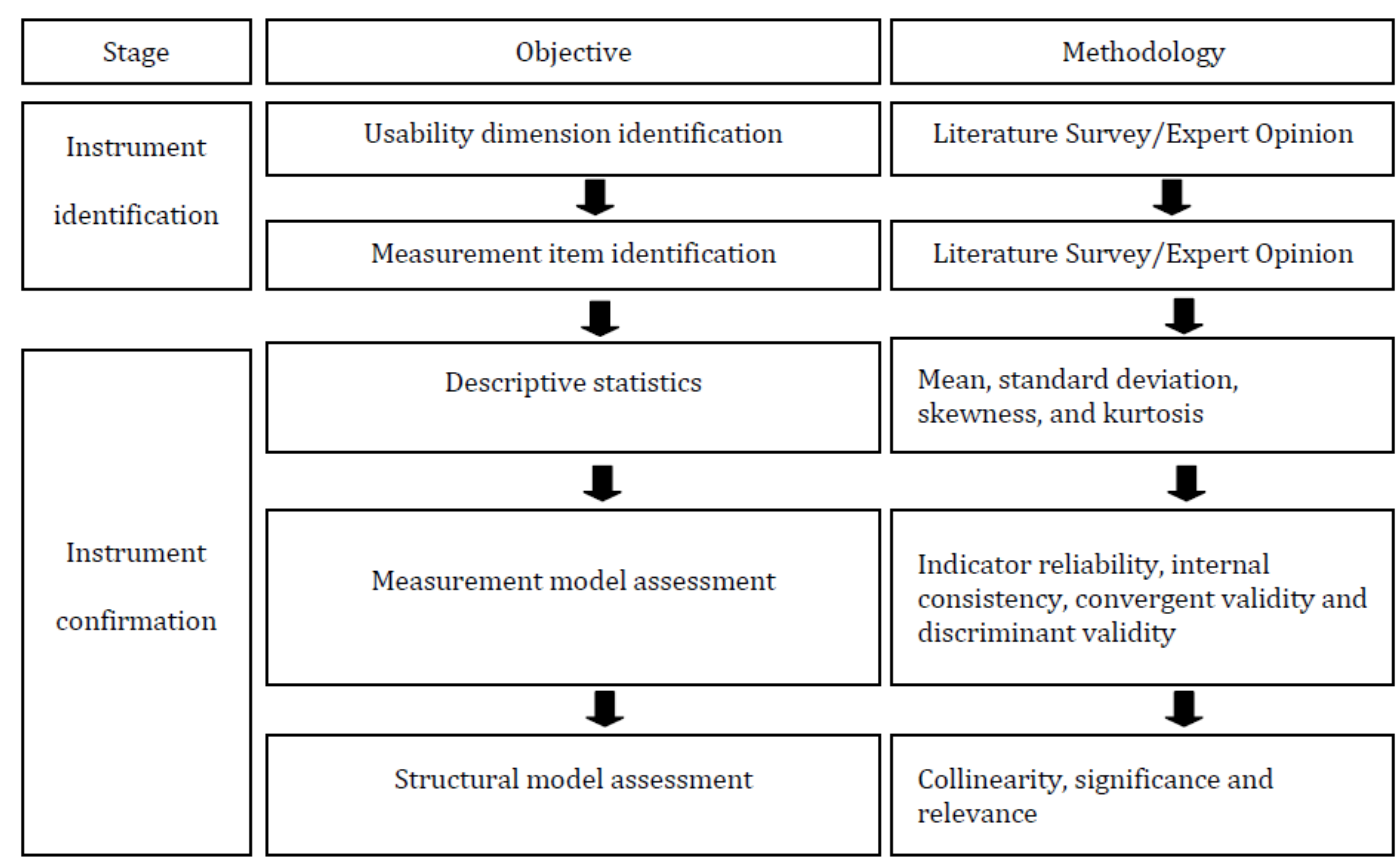

Fig. 1. Process of measurement development.

The process of development was consisted with instrument identification and then instrument confirmation stages. An initial set of measurement instrument including common usability dimensions and measurement items were identified from reviewing relevant previous studies in the instrument identification stage. Herein, two to six measurement items were identified for each dimension by referencing literature reviews and local expert opinions. Afterwards, the identified measurement 
instrument was examined its' reliability and validity using empirical data in the instrument confirmation stage because the instrument items were derived from the previous studies and no any assurance that the items are relevant in Sri Lankan library environment. The descriptive statistics methods and structural equation modelling techniques were used for validation process. According to the DeVellis, the confirmation of instrument is an examination to reduce expenditures and threats from a weak measure [19]. The overall process is summarized in the Fig. 1.

This study surveyed actual users who registered as undergraduate and postgraduate student having real experiences of using the library website at University of Ruhuna in Sri Lanka. The total population of approximate registered students in library is 5000 including 4000 undergraduates and 1000 postgraduate. The required sample size was determined from the Slovin's formula as Eq. (1) [20].

$$
n=N /\left(1+N e^{2}\right)
$$

where, $n=$ sample size, $N=$ total population, $e=$ error tolerance $(0.05)$

So, the required sample size was 370 and the questionnaire was prepared as in both paper and online version because the survey users have experienced with internet services. Previous studies highlighted that web based surveys can be used for collect required data, if research focused users are familiar with internet services [21] while previous researchers also suggested that the data collected through paper and web based surveys remains in equal level [22]. The url of web based questionnaire was sent to library registered users via email and paper based questionnaire was conducted with the users during they visited in the library.

\section{Instrument Development}

\subsection{Usability Dimension Identification}

Table 1. Usability Metrics Used in Prior Research

\begin{tabular}{|c|c|c|c|c|c|c|c|c|c|c|}
\hline 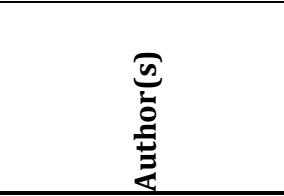 & $\begin{array}{l}\underline{\underline{\Phi}} \\
\underline{\underline{\underline{u}}}\end{array}$ & 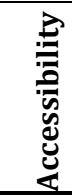 & تُّ & 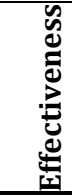 & 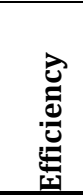 & 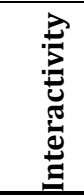 & 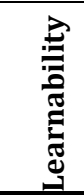 & 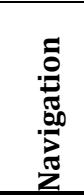 & 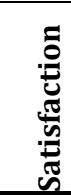 & 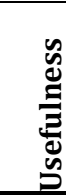 \\
\hline $\begin{array}{l}\text { Buchanan and } \\
\text { Salako }\end{array}$ & [16] & & & $\sqrt{ }$ & $\sqrt{ }$ & & $\sqrt{ }$ & $\sqrt{ }$ & $\sqrt{ }$ & $\sqrt{ }$ \\
\hline Dee and Alain & [23] & $\sqrt{ }$ & & $\sqrt{ }$ & $\sqrt{ }$ & & $\sqrt{ }$ & & $\sqrt{ }$ & $\sqrt{ }$ \\
\hline Hammill & [24] & & $\sqrt{ }$ & & & & & $\sqrt{ }$ & & \\
\hline Hariri and Norouzi & [17] & $\sqrt{ }$ & $\sqrt{ }$ & $\sqrt{ }$ & $\sqrt{ }$ & $\sqrt{ }$ & $\sqrt{ }$ & $\sqrt{ }$ & $\sqrt{ }$ & $\sqrt{ }$ \\
\hline Iqbal and Warraich & [25] & $\sqrt{ }$ & & & $\sqrt{ }$ & & $\sqrt{ }$ & & $\sqrt{ }$ & $\sqrt{ }$ \\
\hline Jeng & [26] & & & $\sqrt{ }$ & $\sqrt{ }$ & & $\sqrt{ }$ & & $\sqrt{ }$ & \\
\hline Joo and Lee & [27] & & & $\sqrt{ }$ & $\sqrt{ }$ & & $\sqrt{ }$ & & $\sqrt{ }$ & \\
\hline Joo, Lin and Lu & [9] & & & $\sqrt{ }$ & $\sqrt{ }$ & & $\sqrt{ }$ & & & \\
\hline Kalra and Vermma & [28] & $\sqrt{ }$ & $\sqrt{ }$ & $\sqrt{ }$ & $\sqrt{ }$ & $\sqrt{ }$ & $\sqrt{ }$ & $\sqrt{ }$ & & \\
\hline Kim & [15] & & & $\sqrt{ }$ & & & & & $\sqrt{ }$ & $\sqrt{ }$ \\
\hline Kling and Elliott & [29] & $\sqrt{ }$ & & & $\sqrt{ }$ & & $\sqrt{ }$ & & & \\
\hline McGillis and Toms & [10] & & & $\sqrt{ }$ & $\sqrt{ }$ & & & & $\sqrt{ }$ & \\
\hline Nathan and Yeow & [30] & & $\sqrt{ }$ & & $\sqrt{ }$ & & & $\sqrt{ }$ & $\sqrt{ }$ & $\sqrt{ }$ \\
\hline Pant & [3] & $\sqrt{ }$ & & $\sqrt{ }$ & $\sqrt{ }$ & & $\sqrt{ }$ & & $\sqrt{ }$ & $\sqrt{ }$ \\
\hline $\begin{array}{l}\text { Raju and } \\
\text { Harinarayana }\end{array}$ & [18] & & $\sqrt{ }$ & $\sqrt{ }$ & $\sqrt{ }$ & & $\sqrt{ }$ & $\sqrt{ }$ & & \\
\hline Rocha & [31] & & $\sqrt{ }$ & & $\sqrt{ }$ & & & & $\sqrt{ }$ & \\
\hline Rogers and Preston & [32] & & & $\sqrt{ }$ & & & $\sqrt{ }$ & & $\sqrt{ }$ & $\sqrt{ }$ \\
\hline Ward and Hiller & [33] & $\sqrt{ }$ & & & $\sqrt{ }$ & & & & & $\sqrt{ }$ \\
\hline $\begin{array}{l}\text { Weinhold, Bekavac } \\
\text { and Hamann }\end{array}$ & [34] & $\sqrt{ }$ & $\sqrt{ }$ & $\sqrt{ }$ & & & $\sqrt{ }$ & & & \\
\hline
\end{tabular}


The usability measurement instrument should be consisted with multiple dimensions to cover the different aspects of usability. So, the study conducted an extensive literature review of academic journals and conference proceedings, web documents, and web usability guidelines to identify dimensions that dominate to the library website usability. Herein, the authors examined a set of thirty-nine key dimensions which was used by different authors to evaluate library related website usability from the prior researches. On analyzing the names and definitions of these key dimensions which have synonyms and homonyms, authors able to decrease the amount of dimensions into nine key dimensions. Table 1 shows the specific usability evaluation dimensions extracted from the prior researches where the dimensions are representing in the columns and authors who proposed this dimension are in the rows.

\subsection{Measurement Items Identification}

Based on the identified dimensions, the standard measurement items consisting of 33 statements which can be used to measure the identified dimensions were drawn from an extensive literature review. The formal and informal discussions were conducted with local experts to determine the relative importance and to ensure the content validity fulfilment of the identified measurement items to the Sri Lankan context and the wordings and format of some measurement items were modified according with local experts' guidance. Further each measurement items were built-up as a declarative statement form on a five point likert-type rating scale ranging from 'strongly disagree $=1$ ' to 'strongly agree $=5$ ' to make the qualitative data quantifiable. Table 2 presents the identified measurement item checklist.

Table 2. Dimensions and Corresponding Measurement Items for Library Website Usability

\begin{tabular}{|c|c|c|c|}
\hline Code & $\begin{array}{l}\text { Usability } \\
\text { Attributes }\end{array}$ & "Definition & Statements/Questions \\
\hline Use1 & \multirow[t]{4}{*}{ Usefulness } & The quality & Accuracy of information on this site is satisfying \\
\hline Use2 & & $\begin{array}{l}\text { having utility and } \\
\text { especially practical }\end{array}$ & $\begin{array}{l}\text { Overall electronic resources provided through the site are } \\
\text { in good level }\end{array}$ \\
\hline Use3 & & worth or & Quality of information on this site is acceptable \\
\hline Use4 & & applicability [16] & $\begin{array}{l}\text { E-reference sources provided through the site are } \\
\text { satisfying }\end{array}$ \\
\hline Effi1 & \multirow[t]{4}{*}{ Efficiency } & Ability of users to & \multirow[t]{3}{*}{ The website is well organized to find what I want } \\
\hline Effi2 & & use the system with & \\
\hline & & high level & \\
\hline & & $\begin{array}{l}\text { productivity [16], } \\
{[17]}\end{array}$ & $\begin{array}{l}\text { I can quickly complete a resource-finding task without any } \\
\text { difficulties }\end{array}$ \\
\hline Effe1 & Effectiveness & $\begin{array}{l}\text { Accuracy and } \\
\text { completeness with } \\
\text { which users achieve }\end{array}$ & $\begin{array}{l}\text { I like to prefer this site as a primary resource to find the } \\
\text { way for getting information regarding my information } \\
\text { needs? }\end{array}$ \\
\hline Effe2 & & goals [26] & I can usually complete a task without getting an error \\
\hline Lea1 & \multirow[t]{4}{*}{ Learnability } & $\begin{array}{l}\text { Ease of learning } \\
\text { such that the user }\end{array}$ & $\begin{array}{l}\text { The terminologies used on this library website were easily } \\
\text { understandable }\end{array}$ \\
\hline Lea2 & & $\begin{array}{l}\text { can quickly begin } \\
\text { using it [9],[26] }\end{array}$ & $\begin{array}{l}\text { I can easily remember how to reach the same page when I } \\
\text { visit next time }\end{array}$ \\
\hline Lea3 & & & It was easy to learn to use this library \\
\hline Lea 4 & & & $\begin{array}{l}\text { This library website provides appropriate help functions } \\
\text { and information }\end{array}$ \\
\hline Sat1 & \multirow[t]{4}{*}{ Satisfaction } & \multirow{4}{*}{$\begin{array}{l}\text { the system should } \\
\text { be pleasant to use, } \\
\text { so that users are } \\
\text { subjectively } \\
\text { satisfied when using } \\
\text { it [15] }\end{array}$} & $\begin{array}{l}\text { I like to recommend this site to my colleagues for getting } \\
\text { information? }\end{array}$ \\
\hline Sat2 & & & $\begin{array}{l}\text { I am comfortable and feel fulfilled while using this library } \\
\text { website }\end{array}$ \\
\hline Sat3 & & & $\begin{array}{l}\text { It is a pleasure to use this library website to find what I } \\
\text { want }\end{array}$ \\
\hline Sat4 & & & I am satisfied with this library overall \\
\hline Acc1 & \multirow[t]{4}{*}{ Accessibility } & \multirow{4}{*}{$\begin{array}{l}\text { Ease of access, fee } \\
\text { for access, stability } \\
{[28],[29]}\end{array}$} & Ease of reading the pages on this site is in good \\
\hline Acc2 & & & Pages loading speed on this site is acceptable \\
\hline Acc3 & & & Visual appeal of the site is satisfying \\
\hline Acc4 & & & Site is in online every time \\
\hline
\end{tabular}




\begin{tabular}{|c|c|c|c|}
\hline $\begin{array}{l}\text { Con1 } \\
\text { Con2 }\end{array}$ & Content & $\begin{array}{l}\text { informational and } \\
\text { transactional } \\
\text { capabilities of the }\end{array}$ & $\begin{array}{l}\text { There are links to branch libraries and other libraries? } \\
\text { There is an archive of previously published materials or } \\
\text { articles? }\end{array}$ \\
\hline Con3 & & website [28] & The textual content and illustrations are up-to-date \\
\hline Con 4 & & & The content is written in an interesting way \\
\hline Con5 & & & Important content is above the page \\
\hline Con6 & & & Ads \& pop-ups are not apparent \\
\hline $\begin{array}{l}\text { Nav1 } \\
\text { Nav2 }\end{array}$ & Navigation & $\begin{array}{lr}\text { Extent to } & \text { which } \\
\text { users } & \text { can } \\
\text { participate } & \text { in }\end{array}$ & $\begin{array}{l}\text { The current location is clearly indicated in each web pages } \\
\text { Structure of the website looks simple without any } \\
\text { unnecessary levels }\end{array}$ \\
\hline Nav3 & & $\begin{array}{l}\text { modifying the form } \\
\text { and content of a }\end{array}$ & $\begin{array}{l}\text { The Home page has included links to access all major parts } \\
\text { of the site }\end{array}$ \\
\hline Nav4 & & $\begin{array}{l}\text { mediated } \\
\text { environment in real } \\
\text { time [30] }\end{array}$ & There is a clearly identified link to the Home page \\
\hline Int1 & Interactivity & $\begin{array}{l}\text { Extent to which } \\
\text { users }\end{array}$ & $\begin{array}{l}\text { Site provides features to gain the users' feedback such as a } \\
\text { site- email address, form, etc }\end{array}$ \\
\hline Int2 & & $\begin{array}{l}\text { participate in } \\
\text { modifying the form } \\
\text { and content of a } \\
\text { mediated } \\
\text { environment in real } \\
\text { time [28] }\end{array}$ & Site offers features for sharing views and discussions \\
\hline Usa1 & Usability & $\begin{array}{l}\text { how easy to use the } \\
\text { website [3] }\end{array}$ & $\begin{array}{l}\text { Do you think this website is easy to use and expected task } \\
\text { can be fulfil without facing any errors }\end{array}$ \\
\hline
\end{tabular}

\section{Results of Analysis}

A survey study was conducted in January 2017 to identify the relative importance of identified usability dimensions and its measurement items with library websites in Sri Lankan environment. A total of 415 complete survey questionnaires were gathered and among them, $45 \%$ were male and rest of them was female. Out of them, $85 \%$ of respondents were undergraduate students.

First, the scales were checked to ensure their appropriateness as a measuring tool from applying descriptive statistical methods (mean, standard deviation, skewness, and kurtosis). Overall, the mean of each item turned out between 3.0 and 4.0, with the standard deviations ranging from 0.63 to 1.10 . The most important dimension is accessibility $(M=3.97, S D=0.72)$ among 9 dimensions while the most unimportant dimension is interactivity $(\mathrm{M}=3.37, \mathrm{SD}=0.92)$. The recommended standard deviations for the 5-point likert scales should be greater than 0.1 for well fit data set. The skewness and kutosis values of the data set were 0.865 and 0.605 respectively. If the absolute values of skewness and kutosis are more than 1.0, then the dataset were considered as unsuitable for measurement instrument validation [27]. So, the descriptive statistical results pointed out the scales applicably for validation process.

Afterwards, the study moved to examine the reliability and validity of identified usability dimensions and its measurement items for Sri Lankan library website context with getting help from SmartPLS 2.0 M. The PLS Algorithm procedure drawn 300 iterations with case wise replacement and path weighting scheme modules, and the bootstrapping procedure draws 415 cases and 1,000 samples, using the no sign change option. According to guidelines given by Hair et al., the measurement models and the structural model were evaluated [35], [36]. An indicator reliability assessment was conducted to assess measurement items reliability and validity. It was found that eight measurement items (acc2, con2, con4, con6, lea3, nav2, sat4, and use3) were below the recommended loading value, i.e., 0.70 . After removing these measurement items, the best measurement models with excellent loading values were obtained. Subsequently, the internal consistency reliabilities of the dimensions were examined by calculating the Cronbach's alpha coefficients while Cronbach's alpha values should be more than 0.85 to accept the internal consistency reliability of the dimensions. Table IV shows the Cronbach's alpha coefficient values for each dimension and two dimensions 
namely, effectiveness and interactivity were removed from the model because they exhibited the required values. After removing them, the reliability of the measurement instrument was succeeded.

Table 3. Values for Adjustment Quality for the SEM Model

\begin{tabular}{lll}
\hline \hline Dimension & Cronbach's Alpha & AVE \\
\hline Accessibility & 0.946913 & 0.904234 \\
Content & 0.965542 & 0.935504 \\
Effectiveness & 0.437172 & - \\
Efficiency & 0.979865 & 0.980220 \\
Interactivity & 0.656698 & - \\
Learnability & 0.994719 & 0.989562 \\
Navigation & 0.855946 & 0.784553 \\
Satisfaction & 0.976763 & 0.955606 \\
Usefulness & 0.992319 & 0.984898 \\
\hline \hline
\end{tabular}

Table 4. Values and Correlations between the Dimensions and Square Roots of the AVE Values in the Main Diagonal

\begin{tabular}{llllllll}
\hline \hline & Accessibility & Content & Efficiency & $\begin{array}{l}\text { Learnabili } \\
\text { ty }\end{array}$ & Navigation & Satisfaction & Usefulness \\
\hline Accessibility & $\mathbf{0 . 9 5 0 9}$ & & & & & & \\
Content & 0.9494 & $\mathbf{0 . 9 6 7 2}$ & & & & & \\
Efficiency & 0.2706 & 0.2846 & $\mathbf{0 . 9 9 0 1}$ & & & & \\
Learnability & 0.3322 & 0.3150 & 0.2409 & $\mathbf{0 . 9 9 4 8}$ & & & \\
Navigation & 0.1671 & 0.1897 & 0.1577 & 0.1563 & $\mathbf{0 . 8 8 5 7}$ & & \\
Satisfaction & 0.1905 & 0.2163 & 0.1950 & 0.3948 & 0.2161 & $\mathbf{0 . 9 7 7 6}$ & \\
Usefulness & 0.9489 & 0.9582 & 0.2629 & 0.3112 & 0.1636 & 0.1978 & $\mathbf{0 . 9 9 2 4}$ \\
\hline \hline
\end{tabular}

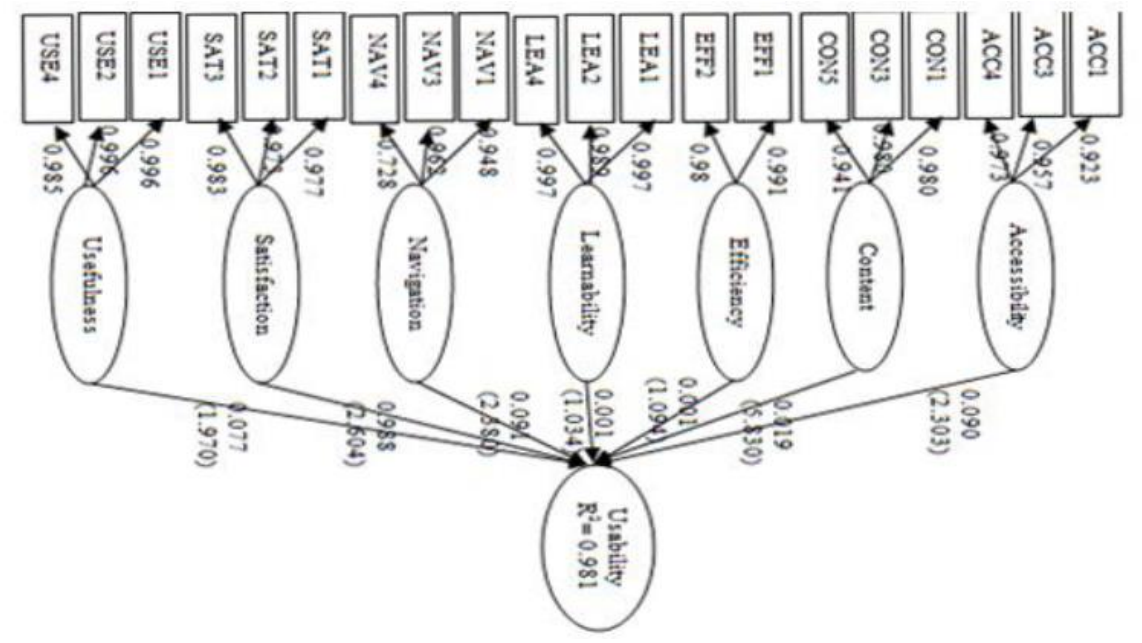

Fig. 2. Structural equation model of usability evaluation instrument for library website.

Next, the convergent validity which measures the extent to which a dimension converges in its indicators by explaining the items' variance of each dimension was examined and if it is high, then dimensions correlate highly with each other [4]. The convergent validity is considered to be acceptable level when average variance extracted (AVE) value is greater than or equal to 0.50. The AVE values for each dimension are shown in Table 3, and the all AVE values for this model exceeded 0.50. Next step was to examine the discriminant validity of the model. Discriminant validity refers to the extent to which a dimension and its measurement items differ from other dimensions and their measurement items [4]. Discriminant validity status was examined using Fornell and Larcker's criteria which compare the square roots of the AVE values of each dimension with the correlations between the dimensions and the square roots of the AVEs should be greater than the correlations between the dimensions. Table 4 shows the values for the correlations 
between dimensions and the square roots of the AVE values and the results indicate clear discriminant validity among these dimensions.

The final step was to measure the significance and relevance of the structural model relationships. Fig. 2 shows the proposed usability evaluation model for library websites, including the resulting values of $\mathrm{R}^{2}$, path loadings, and t-values for all dimensions. A large amount of variance in usability $\left(R^{2}=0.981\right)$ has defined the model's successful and all dimensions are strongly influenced with usability including five of seven significant structural relationships. Therefore, the construct validity and reliability of the identified measurement instrument was verified from the results of confirmatory factor analysis using SEM and the final model was consisted with seven usability measuring dimensions including, accessibility, content, efficiency, learnability, navigation, satisfaction, and usefulness together with 20 measurement items to measure the seven conceptual dimensions.

\section{Discussion and Implications}

Website usability is considered as the most important factor for website success but there has no sufficient researches found from the library related website usability evaluation studies in the literature. Developing a usable and effective library website is challenging task to success, maintaining and redesigning a website to meet the constantly changing user needs is a seemingly impossible task. Thus usability testing is expected to achieve this task as it not only support identifying interface problems but also help development ways and means that would solve those problems. The available literature is attested that there is no any fixed criterion for usability evaluation process because many of the prior researches were discussed it in different aspects. In addition, heuristic evaluation methods, user surveys, and user observations were also used to evaluate the usability of library websites as well as different type and amount of usability dimensions were undertaken for measurement development.

This study attempts to identify the elementary measurement instrument to be able to evaluate library website usability level in Sri Lanka from a comprehensive investigation of the relative importance of usability dimensions suggested in literature. Then, the study examined the identified measurement instrument's reliability and validity with the Sri Lankan library context using factor analysis and structural equation modelling methods. Testing usability with a different set of dimensions of a website will gain more benefits for librarians. Moreover, librarians have a possibility to identify weakness areas of their website that should be improve to give better service quality from the results given by the instrument. The results attest that the dimensions included in the instrument are comparatively good indicators with different impacts for library website usability evaluation. Furthermore, the results of the usability studies can be useful to identify the user's intention to use of the website while the motivation of the study was to better understand of relational importance of website usability dimensions and its role in a user's acceptance level of a website. Website usability measuring instrument allows librarians to set up standards by examining the present usability status of the websites with their relatives. Therefore, measuring website usability using a valid and reliable research instrument will get benefits for both staff and users of libraries.

The scientific evidence of the study gives a more practical direction to the librarians on the more impactful website usability factors that lead to successfully allocate their limited resources to create more successful and useful websites. Furthermore, the proposed instrument will guide as a standard library website design guideline that can be useful to develop usable library related websites while it also is cost effective in comparison with other usability evaluation methods. The paper encourages other libraries to identify the strengths and weaknesses of their websites usability and users' awareness for the website using similar website usability evaluation with limited budget. Finally, Levi and Conrad said that "there has no any doubt in our minds about our website's reliability because we designed our website accordingly to 
the results of usability evaluation and always users have satisfied with our website" [37].

\section{Conclusion}

A significant understanding of awareness and willingness of users cannot be done without a proper investigation of website usability. The present study aimed to confer with literature concerning library website in order to identify website usability dimensions and measurement items that can be directly applied to library website usability evaluation domain in Sri Lanka. The reliability and validity of identified dimensions and measurement items were then empirically examined from actual users in university library in Sri Lanka. The final usability evaluation model was build-up with seven dimensions along with two to three measurement items to measure each dimension. The results of this study can be used as building block for how website usability measurement tool may be understood, defined, empirically examined, and used in both research and practice as an important tool for evaluating website usability in specific domain. Therefore, the main knowledge contribution of this study will serve as a measuring instrument that draws the attention of librarians to set of important usability dimensions that should be considered when designing their websites so as to meet the user expectations. Finally, such usability evaluation model can serve as a guideline for evaluating websites usability and assist website designers in building more usable websites and adds to the literature on the important topic of usability.

In the next phase of this research, the authors plan to continue working with the identified key dimensions and measuring items to explore the relative importance of each dimension and measuring items of interest while avoiding uncertainty, and ambiguity with the aids of experts in the related field and finally to develop an automated library website usability evaluation framework based on the combination of fuzzy AHP and comprehensive evaluation methods.

\section{Acknowledgement}

The authors would like to convey their sincere gratitude to all those who have significantly contributed towards the completion of this article.

\section{References}

[1] Babu, B. R., Jeyshankar, R., \& Rao, P. N. (2010). Websites of central universities in India : A webometric analysis. DESIDOC Journal of Library \& Information Technology, 30(4), 33-43.

[2] Shadpour, P., Teimourpour, B., \& Asadi, R. (2013). Webometrics-based analysis and ranking of Iranian hospital websites. Int J Hosp Res, 2(2), 77-84. Retrieved from http://ijhr.iums.ac.ir/jufile?c2hvd1BERj01NzQ3J19hY3Rpb249c2hvd1BERiZhcnRpY2xlPTU3NDcmX29 iPWZIMjRmNDJiYzI4NDQ3YTMzODNmNzlmMmM1Y2IyNTll

[3] Pant, A. (2015). Usability evaluation of an academic library website. The Electronic Library, 33(5), 896915.

[4] Lee, Y., \& Kozar, K. A. (2012). Understanding of website usability: Specifying and measuring constructs and their relationships. Decision Support Systems, 52(2), 450-463.

[5] Nielsen, J. (2012). Usability 101: Introduction to Usability. Retrieved from https://doi.org/10.1145/1268577.1268585

[6] Becker, S. A., \& Mottay, F. E. (2001). A global perspective on web site usability. IEEE Software, 18(1), 5461.

[7] Nagpal, R., Mehrotra, D., Bhatia, P. K., \& Sharma, A. (2015). FAHP approach to rank educational websites on usability. International Journal of Computing and Digital System, 4(4), 251-260.

[8] Battleson, B., Booth, A., \& Weintrop, J. (2001). Usability testing of an academic library web site: A case 
study. Journal of Academic Librarianship, 27(3), 188-198.

[9] Joo, S., Lin, S., \& Lu, K. (2011). A usability evaluation model for academic library websites: Efficiency, effectiveness and learnability. Journal of Library and Information Studies, 9(2), 11-26.

[10] McGillis, L., \& Toms, E. G. (2001). Usability of the academic library web site : Implications for design. College Research Libraries, 62(4), 355-367.

[11] Raward, R. (2001). Academic library website design principles: Development of a checklist. Australian Academic \& Research Libraries, 32(2), 123-136.

[12] George, C. A. (2005). Usability testing and design of a library website: An iterative approach. OCLC Systems \& Services: International Digital Library Perspectives, 21(3), 167-180.

[13] Jeffcoat King, H., \& Jannik, C. M. (2005). Redesigning for usability. OCLC Systems \& Services: International Digital Library Perspectives, 21(3), 235-243.

[14] Turnbow, D., Kasianovitz, K., Snyder, L., Gilbert, D., \& Yamamoto, D. (2005). Usability testing for web redesign: A UCLA case study. OCLC Systems \& Services: International Digital Library Perspectives, 21(3), 226-234.

[15] Kim, Y. M. (2011). Users' perceptions of university library websites: A unifying view. Library and Information Science Research, 33(1), 63-72.

[16] Buchanan, S., \& Salako, A. (2009). Evaluating the usability and usefulness of a digital library. Library Review, 58(9), 638-651.

[17] Hariri, N., \& Norouzi, Y. (2011). Determining evaluation criteria for digital libraries' user interface: A review. The Electronic Library, 29(5), 698-722.

[18] Raju, V., \& Harinarayana, N. S. (2008). An analysis of usability features of library web sites. Annals of Library and Information Studies. Retrieved from http://www.niscair.res.in/ScienceCommunication/ResearchJournals/rejour/annals/annals2k8/alis_ju n08.asp\#111

[19] DeVellis, R. F. (1991). Scale development: Theory and application (2nd ed.). Thousand Oaks, CA: Sage.

[20] Ellen, S. (2012). Slovin's Formula Sampling Techniques. Retrieved from http://sciencing.com/slovinsformula-sampling-techniques-5475547.htm

[21] Tan, M., \& Teo, T. (2000). Factors influencing the adoption of internet banking. Journal of the Association for Information Systems, 1, 1-42.

[22] Meyerson, P., \& Tryon, W. W. (2003). Validating internet research: A test of the psychometric equivalence of internet and in-person samples. Behavior Research Methods, Instruments, \& Computers, 35(4), 614-620.

[23] Dee, C., \& Allen, M. (2006). A survey of the usability of digital reference services on academic health science library web sites. The Journal of Academic Librarianship, 32(1), 69-78.

[24] Hammill, S. J. (2003). Usability testing at florida international university libraries: What we learned. Electronic Journal of Academic and Special Librarianship, 4(1).

[25] Iqbal, M., \& Warraich, N. F. (2012). Usability evaluation of an academic library website: A case of the university of the Punjab. Pakistan Journal of Library and Information Science, 13(13).

[26] Jeng, J. (2005). Usability assessment of academic digital libraries: Effectiveness, efficiency, satisfaction, and learnability. Libri, 55(2-3), 96-121.

[27] Joo, S., \& Yeon Lee, J. (2011). Measuring the usability of academic digital libraries. The Electronic Library, 29(4), 523-537.

[28] Kalra, J., \& Verma, R. K. (2011). Evaluation indicators of library websites of selected research institutions in India. Annals of Library and Information Studies, 58(2), 139-150.

[29] Kling, R., \& Elliott, M. (1994). Digital library design for organizational usability. ACM SIGOIS Bulletin, 
15(2), 59-70.

[30] Nathan, R. J., \& Yeow, P. H. P. (2011). Crucial web usability factors of 36 industries for students: A largescale empirical study. Electronic Commerce Research, 11(2), 151-180.

[31] Rocha, Á. (2012). Framework for a global quality evaluation of a website. Online Information Review, 36(3), 374-382.

[32] Rogers, R., \& Preston, H. (2009). Usability analysis for redesign of a caribbean academic library web site: a case study. OCLC Systems Services, 25(3), 200-211.

[33] Ward, J. L., \& Hiller, S. (2008). Usability testing, interface design, and portals. Journal of Library Administration, 43(1-2), 155-171

[34] Weinhold, T., Bekavac, B., \& Hamann, S. (2014). BibEval-A framework for usability evaluations of online library services. Libraries in the Digital Age (LIDA). Retrieved from http://ozk.unizd.hr/proceedings/index.php/lida/article/view/113

[35] Hair, J. F., Ringle, C. M., \& Sarstedt, M. (2012). Partial least squares: The better approach to structural equation modeling? Long Range Planning, 45(5-6), 312-319.

[36] Hair, J. F., Ringle, C. M., \& Sarstedt, M. (2011). PLS-SEM: Indeed a silver bullet. The Journal of Marketing Theory and Practice, 19(2), 139-152.

[37] Levi, M., \& Conrad, F. (1997). Usability Testing of World Wide Web Sites. Retrieved from http://www.bls.gov/ore/htm_papers/st960150.htm

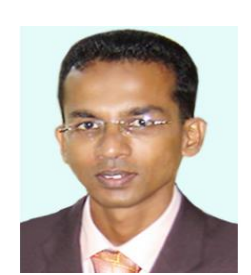

Kokila Harshan Ramanayaka received the B.Sc degree from University of Ruhuna, Sri Lanka in 2001 and M.Sc degree in library and information sciences from University of Kelaniya, Sri Lanka in 2014. He is currently pursuing the Ph.D at School of Computer Science and Technology, Wuhan University of Technology, P.R. China. His main research directions include web mining, human computer interaction, and software engineering.

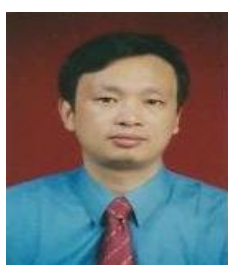

Xianqiao Chen is currently a professor, in the School of Computer Science and Technology and the director in the Institute of Things at the Wuhan University of Technology, P. R. China. His main research directions include image processing, pattern recognition, simulation, communications and control, internet of things, GIS and software engineering.

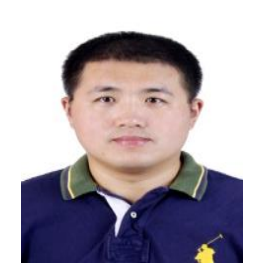

Bing Shi is an associate professor in the School of Computer Science and Technology, Wuhan University of Technology, P. R. China. His main research directions include artificial intelligence, multi-agent systems, software engineering and so on. 